\title{
Galvanostatic Intermittent Titration Study of the Positive Electrode of a $\mathrm{Na} \mid \mathrm{Ni}(\mathrm{Fe})$-Chloride Cell
}

\author{
Ruixing Zhu, ${ }^{a}$ Michael Vallance, ${ }^{\mathrm{b}}$ Saeed Khaleghi Rahimian, ${ }^{\mathrm{a}}$ and Alan C. West ${ }^{\mathrm{a}, *, \mathrm{z}}$ \\ ${ }^{a}$ Department of Chemical Engineering, Columbia University, New York, New York 10027, USA \\ ${ }^{b}$ General Electric Global Research Center, Niskayuna, New York 12309, USA
}

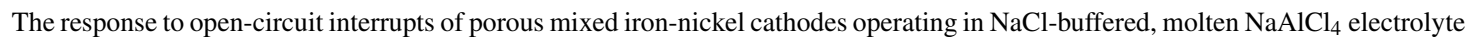
has been characterized as a function of state of charge (SOC) for different iron loadings and different charge and discharge rates. After discharge, the open-circuit potential (OCP) can evolve in time from the iron plateau to the nickel plateau, and this behavior can be explained by galvanic interactions between iron metal and $\mathrm{Ni}^{2+}$. Characteristic times of the OCP transients depend on $\mathrm{SOC}$ and can be large. When the OCP has converged on a steady state during discharge, its value may provide an estimate of the mole fraction of $\mathrm{NiCl}_{2}$ at the interface of the triclinic $(\mathrm{Ni}, \mathrm{Fe}) \mathrm{Cl}_{2}$ film that resulted from metal oxidation. Detailed analyses of the experiment require modeling of the galvanic conversion rates, which depend on both charge-transfer and mass-transfer phenomena.

(C) The Author(s) 2015. Published by ECS. This is an open access article distributed under the terms of the Creative Commons Attribution Non-Commercial No Derivatives 4.0 License (CC BY-NC-ND, http://creativecommons.org/licenses/by-nc-nd/4.0/), which permits non-commercial reuse, distribution, and reproduction in any medium, provided the original work is not changed in any way and is properly cited. For permission for commercial reuse, please email: oa@electrochem.org. [DOI: 10.1149/2.0471510jes] All rights reserved.
\end{abstract}

Manuscript submitted June 22, 2015; revised manuscript received July 16, 2015. Published July 28, 2015.

The high-performance sodium metal chloride battery has garnered significant interest in the past decade due to its multiple advantages. The high energy density of the battery $(90 \mathrm{Wh} / \mathrm{kg})$ positions it as an attractive and economical alternative for stationary storage applications. $^{1-3}$ Furthermore, because of its relatively high power density of $150 \mathrm{~W} / \mathrm{kg}$, the technology has also been considered for transportation applications. ${ }^{4}$ In addition, the sodium/metal-chloride battery has a long life, a deep discharge cycling ability, a high safety level, $100 \%$ coulombic efficiency, and a broad ambient-temperature operating range..$^{5-9}$

The cell is assembled in a fully discharged state. Once heated (260$340^{\circ} \mathrm{C}$ ) and charged, it contains a liquid sodium anode separated from the positive electrode by a ceramic sodium-conducting $\beta^{\prime \prime}$-alumina solid electrolyte (BASE). The positive electrode contains iron, nickel, or both, as well as $\mathrm{NaCl}$ and a secondary electrolyte $\mathrm{NaAlCl}_{4}$. When fully discharged, the positive electrode has a typical porosity of $60 \%$. Excess transition-metal (M, where $\mathrm{M}$ is $\mathrm{Fe}$ or $\mathrm{Ni})$ ) powder is added to these cells to facilitate three-dimensional electronic conductivity inside the cathode. ${ }^{7}$ The overall cell reaction is given by:

$$
2 \mathrm{NaCl}+\mathrm{M}=2 \mathrm{Na}+\mathrm{MCl}_{2}
$$

Most commercial cells are comprised of a nickel positive electrode, in part because of the higher oxidation potential and the lower active species solubility of nickel, compared to iron. However, the nickel cathode is often combined with a small mass fraction of iron, as this improves cell performance, especially in applications demanding high discharge pulse power at low states of charge. ${ }^{7}$ The presence of the iron in the electrode improves performance, but significantly increases the complexity of the reaction kinetics of the cathode.

In a companion study, we discussed key features of the constantrate charge and discharge behavior of mixed Ni-Fe chloride cells. ${ }^{10}$ The cell potential, as a function of SOC, depends on a large number of factors; but from a simple perspective, during charge, the iron is first oxidized to sparingly soluble $\mathrm{FeCl}_{2}$ at a potential near $2.34 \mathrm{~V}$ (vs. $\mathrm{Na} / \mathrm{Na}^{+}$) at $300^{\circ} \mathrm{C}$ until "completion" and then the nickel is oxidized to insoluble $\mathrm{NiCl}_{2}$ at near $2.60 \mathrm{~V}$. In contrast, during discharge, $\mathrm{NiCl}_{2}$ is reduced on the nickel plateau, but the transition to the iron plateau occurs before the $\mathrm{NiCl}_{2}$ is fully reduced. This has been explained by assuming a mass transfer limitation associated with solid-state diffusion of nickel ion to the electrode.

In this work, open-circuit potentials of the cathode material are measured with the galvanostatic intermittent titration technique ${ }^{11,12}$

*Electrochemical Society Active Member.

${ }^{\mathrm{z}}$ E-mail: acw7@ columbia.edu
(GITT). GITT has been employed as a means of elucidating the mechanisms by which iron and nickel interact in these systems, allowing for model validation. While measurements were performed over the entire range of the SOC during charge and discharge, the most complex and interesting dynamic behavior was observed on the iron plateau during discharge, where both iron and nickel reduction reactions proceed. The use of GITT may provide complementary means to explore the influence of mass-transfer and charge-transfer effects on battery performance, allowing for further electrode optimization, and the method could be a simple-to-implement diagnostic tool for $\mathrm{Na} / \mathrm{Ni}(\mathrm{Fe})$-halide cell studies. Experimental results are presented for different cathode compositions and rates.

\section{Experimental}

The cell design was described previously. ${ }^{10}$ In short, the counterelectrode, contained in the bottom of a borosilicate glass flask, is a coil of 2-mm-diameter nickel wire (99.98\%, Alfa Aesar), covered in $5 \mathrm{~g}$ of aluminum flakes (granular, $99.7 \%$, Sigma Aldrich), $5 \mathrm{~g}$ of sodium chloride, and $30 \mathrm{~g}$ of $\mathrm{NaAlCl}_{4}$ (powder, 99.99\%, Sigma Aldrich). The positive electrode is built in a flat-bottom, H3-size, Ionotec sodium-conducting $\beta^{\prime \prime}$ - alumina tube (H3-80-LN, Ionotec); with the bottom of the tube resting on the counter electrode. The current is assumed to flow through the bottom face, which has an area of $0.3 \mathrm{~cm}^{2}$. The positive-electrode current collector is a coil of 0.5-mm-diameter molybdenum wire $(99.95 \%$, Alfa Aesar) covered by a layer of molybdenum gauze (50 mesh, Alfa Aesar). A reference electrode; a slender, closed-end, borosilicate glass tube containing a 1-mm-diameter aluminum wire, $100 \mathrm{mg}$ of sodium chloride, and 100 mg of $\mathrm{NaAlCl}_{4}$; is inserted into the granulated, packed-bed cathode. ${ }^{13}$ The cell is built and operated in an argon-atmosphere glove box, by first loading the counter electrode components into the flask and then heating to the desired temperature $\left(300^{\circ} \mathrm{C}\right)$. Temperature is controlled with a thermocouple sheathed in a borosilicate glass tube, which is positioned in the $\mathrm{NaAlCl}_{4}$ of the counter electrode.

Cathode granules were fabricated from nickel powder (Type 255, Novamet), microfine sodium chloride powder (custom powder, British Salt), sodium iodine powder (99.999\%, Sigma Aldrich), aluminum power (325 mesh, 99.97\%, Alfa Aesar) and reagent grade powders of iron ( $<10$ microns, $99.9+\%$, Alfa Aesar). The materials were combined and homogenized in a tumbling mixer within a glove box. The mixture was granulated on a roll compactor (Alexanderwerk BT-120) and a granulator (Vector TFC-Lab). The materials were then loaded into sieves which classified the granules into the size range of $2 \mathrm{~mm}$ to $212 \mu \mathrm{m}$. Three different granule compositions (3 wt $\%, 8 \mathrm{wt} \%$ and 


$\begin{aligned} & \text { Table I. Mass fractions of positive electrode materials. The } \\
& \text { aluminum is assumed to be consumed during the maiden charge. }\end{aligned}$
\begin{tabular}{cccc} 
Composition & $3 \mathrm{wt} \% \mathrm{Fe}$ & $8 \mathrm{wt} \% \mathrm{Fe}$ & $10 \mathrm{wt} \% \mathrm{Fe}$ \\
\hline $\mathrm{NaCl}$ & 0.341 & 0.343 & 0.344 \\
$\mathrm{Ni}$ & 0.621 & 0.567 & 0.544 \\
$\mathrm{Fe}$ & 0.030 & 0.082 & 0.104 \\
$\mathrm{Al}$ & 0.005 & 0.005 & 0.005
\end{tabular}

$10 \mathrm{wt} \% \mathrm{Fe}$ ) were tested. Table I provides a summary of the compositions of the three electrodes.

The positive electrode is built by pouring $1 \mathrm{~g}$ of granulated metals and salts, and $3 \mathrm{~g}$ of pulverized $\mathrm{NaAlCl}_{4}$, into the bottom of the BASE tube. Twenty-five grams of yttria-stabilized zirconium-oxide beads $(\mathrm{d}=5 \mathrm{~mm}$, Alfa Aesar) are subsequently placed on top of the positive electrode material to aid granule-granule contact. The aluminum reacts with sodium chloride during the first cycle. ${ }^{14}$ The cell is never discharged below $0.20 \mathrm{~V}$ (vs. $\mathrm{Al} / \mathrm{Al}^{3+}$ ), so aluminum is not re-plated.

Cell testing was performed with an Ivium-n-stat electrochemical test system. For reference, the aluminum reference electrode potential is $1.58 \mathrm{~V}$ versus the $\mathrm{Na} / \mathrm{Na}^{+}$anode of commercial battery cells, and all measured potentials are reported vs. the reference electrode. The same cell cycling protocol from the previous work was applied in the present study. ${ }^{10}$ In all cases, there were 10 deep, constant-current charge/discharge cycles at $50 \mathrm{~mA}$ used to "precondition" the electrode, prior to data collection. The charge data were obtained from fully discharged cells by constant-current charging at $50 \mathrm{~mA}, 100 \mathrm{~mA}$, $250 \mathrm{~mA}$ or $500 \mathrm{~mA}$ to a $1.2 \mathrm{~V}$ cutoff voltage. The discharge data at the same rates were obtained from fully charged cells. Full charge was achieved via constant current charging followed by constant voltage charging until the current decreased to $2 \mathrm{~mA}$. The discharge cutoff potential was $0.2 \mathrm{~V}$. Figure 1 shows the charge and discharge curves at rates of $50 \mathrm{~mA}$ for $3 \mathrm{wt} \%, 8 \mathrm{wt} \%$ and $10 \mathrm{wt} \% \mathrm{Fe}$. Two voltage plateaus were seen because of the two electrochemical reactions, corresponding to nickel and iron redox. Discrepancies between charge and discharge potential plateau sizes were observed. Using $3 \mathrm{wt} \% \mathrm{Fe}$ cathode as an example, the nickel plateau is approximately $350 \mathrm{C}$ during charge and is $\sim 280 \mathrm{C}$ during discharge. The reasons for the size differences are attributed to mass-transfer limitations of the nickel chloride-reduction reaction. ${ }^{10}$

The GITT measurements were conducted using the same preconditioning and charge/discharge protocols. However, in the GITT experiment, the current was interrupted every $15 \mathrm{C}$ near the transition between the iron and nickel plateaus. For example, the $8 \mathrm{wt} \%$ $\mathrm{Fe}$ cell was first interrupted after $55 \mathrm{C}$ charging and $190 \mathrm{C}$ discharging. Typically, the resulting potential transient was monitored for $300 \mathrm{~s}$; then the current was reapplied at the previous level $(50 \mathrm{~mA}$, $100 \mathrm{~mA}, 250 \mathrm{~mA}$ or $500 \mathrm{~mA}$ ) and the on-off cycles continued. Discharge GITT data were measured during discharge after the cell was charged including the charge GITT protocol. In some cases, interrupt times were increased to $1800 \mathrm{sec}$ to allow the OCP to equilibrate more completely.

\section{Results}

Figure 2 shows the results of GITT studies on an $8 \mathrm{wt} \% \mathrm{Fe}$ positive electrode. Following the preconditioning described in the Experimental section, the electrode was charged at a rate of $50 \mathrm{~mA}$ with open-circuit interrupts every $15 \mathrm{C}$ starting at $55 \mathrm{C}$, and one at the top of charge. Figure $2 b$, shows the three transients marked in Figure 2a in more detail. Here, the time is measured from the last instant at which the current was turned on, and each curve shows the potential transient during the applied current and then during the interrupt. Curves $i$ and iii correspond to behavior when on the nickel plateau and the iron plateau, respectively. Curve $i i$ was taken during the transition from the iron to nickel plateaus. The relatively large variation in OCP seen
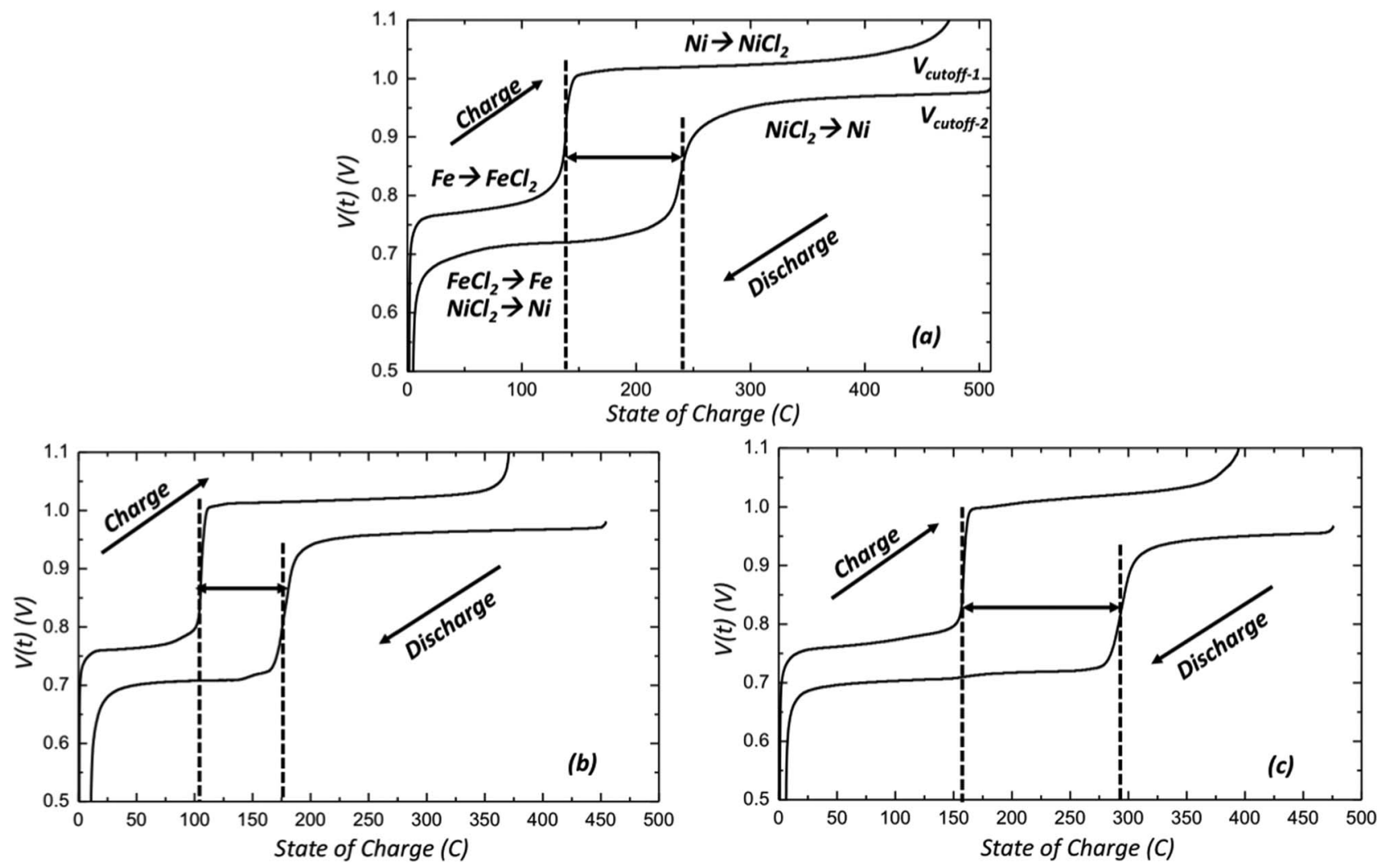

Figure 1. Cell potentials during constant-current at $50 \mathrm{~mA}$ charge and discharge. Results are shown for (a) $8 \mathrm{wt} \%$, (b) $3 \mathrm{wt} \%$ and (c) $10 \mathrm{wt} \%$ Fe porous cathodes. The vertical dashed lined highlights the discrepancy in size between charge and discharge of the "iron" plateau. 

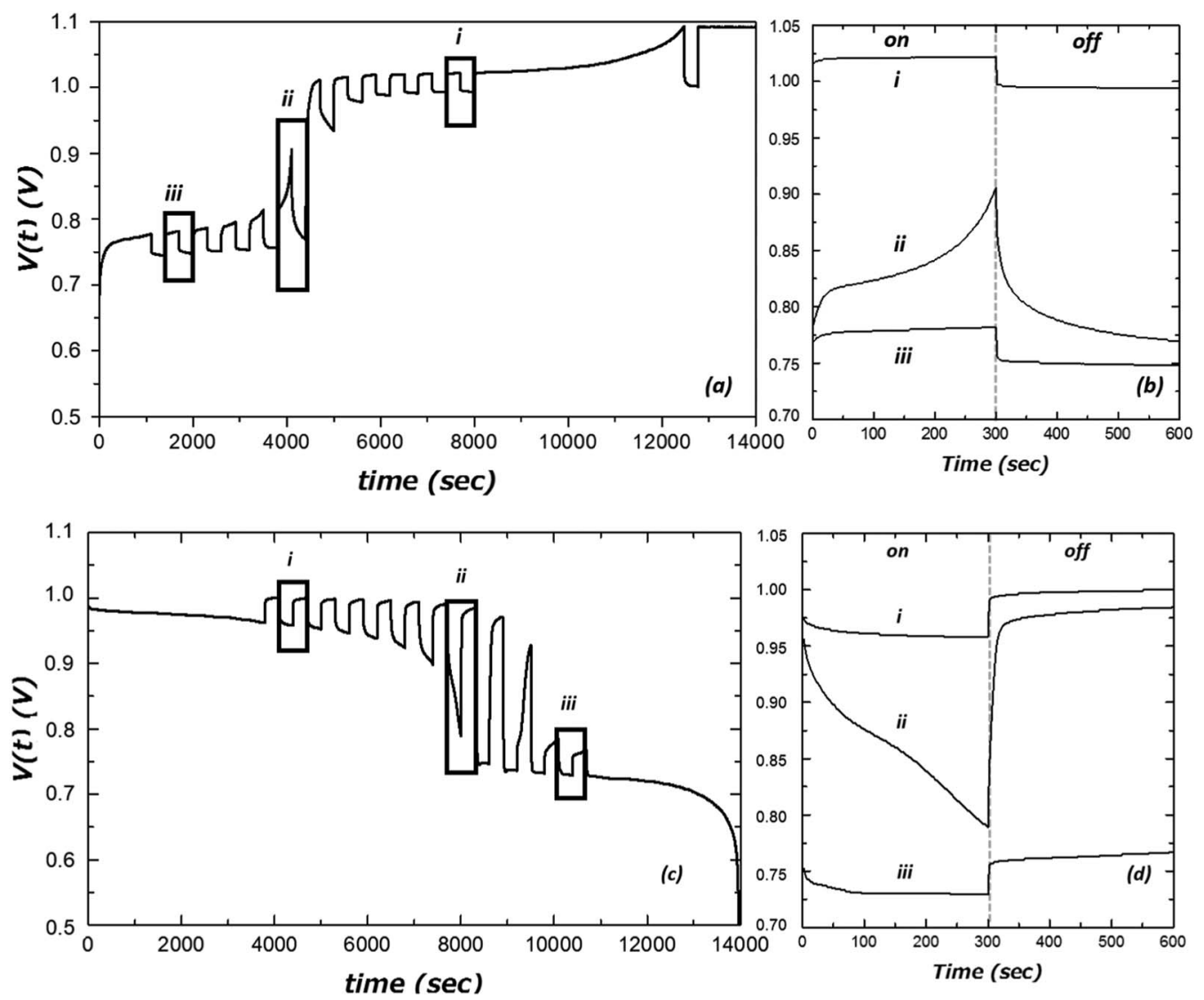

Figure 2. Cell potential in GITT experiment as a function of open-circuit time for a half-cell with 8 wt $\%$ Fe positive electrode at (a) $50 \mathrm{~mA}$ charge rate and (c) $50 \mathrm{~mA}$ discharge rate. Zoomed-in figures (b) and (d) show the potential transients corresponding to the regions $i$, ii, and iii.

in curve ii reflects galvanic interactions between $\mathrm{NiCl}_{2}$ and $\mathrm{Fe}$, which are discussed below for discharge GITT measurements.

Once the cell was charged with the GITT protocol, it was discharged at a rate of $50 \mathrm{~mA}$, with open-circuit interrupts every $15 \mathrm{C}$ starting at $190 \mathrm{C}$ discharged. The cell potential during discharge begins at near $1.00 \mathrm{~V}$ at $100 \%$ SOC. When the current stops, the potential abruptly increases and then slowly converges to an apparently steady value. Figure $2 d$, shows in more detail the three transients marked in Figure 2c. Here, the time is measured from the last instant at which the current was turned on, and each curve shows the potential transient during the applied current and then during the interrupt. Curves $i$ and iii correspond to behavior when on the nickel plateau and the iron plateau, respectively. Curve $i i$, taken at a time of $7700 \mathrm{~s}$, shows representative behavior obtained where the discharge curve transitions from the nickel to the iron plateaus. In many cases, as seen in curve $i$, the potential relaxes back to the $\mathrm{Ni} / \mathrm{NiCl}_{2}$ potential:

$$
\mathrm{NiCl}_{2}+2 \mathrm{e}^{-}=\mathrm{Ni}+2 \mathrm{Cl}^{-} \quad U^{\theta}=1.00 \mathrm{~V} \text { vs } \mathrm{Al}
$$

This suggests that, while some $\mathrm{NiCl}_{2}$ reactant remains within the porous electrode construct, the rate of reduction of the nickel ion is insufficient to maintain the current (galvanostatic control). The iron reduction reaction then proceeds, and this occurs at a significantly lower cell potential:

$$
\mathrm{FeCl}_{2}+2 \mathrm{e}^{-}=\mathrm{Fe}+2 \mathrm{Cl}^{-} \quad U^{\theta}=0.74 \text { V vs Al }
$$

While during discharge the potential assumes a value to allow iron reduction, during the open-circuit relaxation the potential reverts to a value corresponding to nickel reduction.

Figure 3 shows GITT data obtained during discharge for the $8 \mathrm{wt} \% \mathrm{Fe}$ cathode at two discharge rates, plotted now as a function of SOC. The measurements reported herein are focused on the transition between the two plateaus. Experiments were performed at
100 and $500 \mathrm{~mA}$ as well, but results are not shown in the graph for clarity; note that at higher rates, the potential transition is less abrupt. Since these are discharge curves, the time progresses from high SOC to low SOC. When comparing the two curves while the current is on, the difference in the potential is related to the surface and ohmic overpotential differences associated with a $5 \times$ difference in discharge rate. The magnitude of the relaxations to higher potential is generally larger for the higher rate. However, at least near the transition, the final value of the OCP is similar for the two cases, approaching values for the reversible $\mathrm{Ni} / \mathrm{NiCl}_{2}$ potential. Even the relatively slow $50-\mathrm{mA}$ discharge exhibits OCP relaxation back to the $\mathrm{Ni} / \mathrm{Ni}^{++}$level after

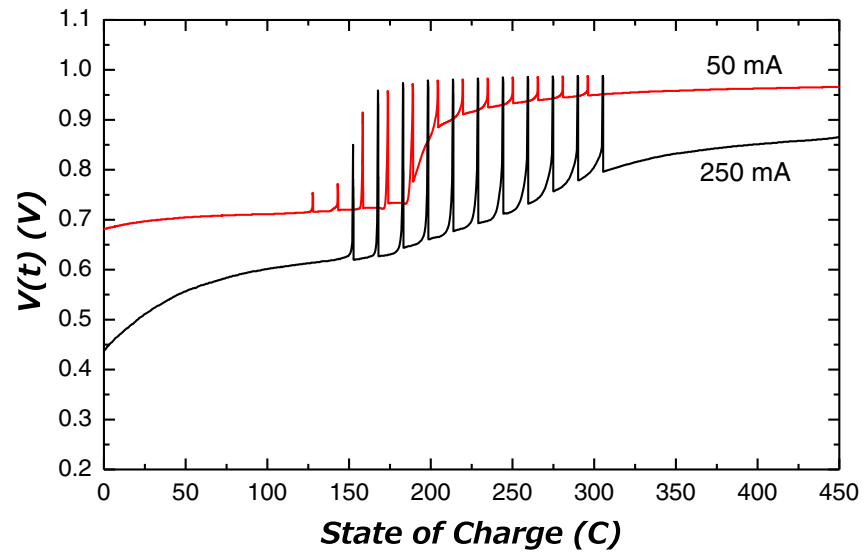

Figure 3. Cell potential as function of the state of charge (SOC) for an $8 \mathrm{wt} \%$ Fe positive electrode at low $(50 \mathrm{~mA})$ and high $(250 \mathrm{~mA})$ discharge rates. 

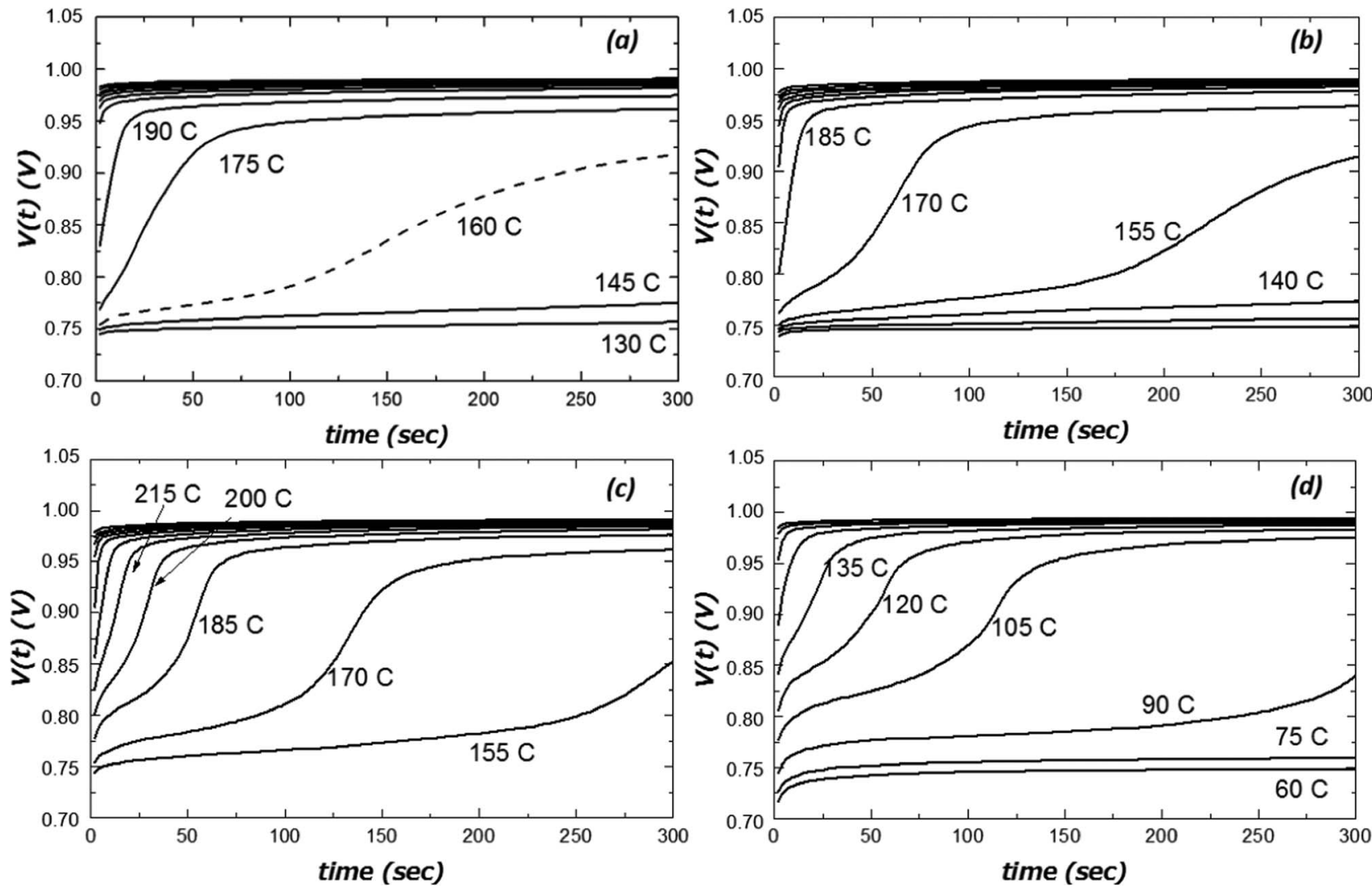

Figure 4. Open circuit potential as a function of time for different SOC (indicated in the figure). All results are for an 8 wt $\%$ Fe positive electrode during discharge at rates of (a) $50 \mathrm{~mA}$, (b) $100 \mathrm{~mA}$, (c) $250 \mathrm{~mA}$, and (d) $500 \mathrm{~mA}$

discharge onto the iron plateau. At high SOC, the potential relaxes to the Ni potential and at low SOC, the potential relaxes to the iron plateau.

Experiments of the type shown in Figures 2 and 3 were obtained for multiple compositions and rates. Figure 4 shows transients obtained at four discharge rates. It can be seen that in the initial stages of discharge, there is a rapid transient, with a time constant that grows as SOC decreases. For still lower SOC, such as $155 \mathrm{C}$ in Figure $4 \mathrm{~b}$, the potential relaxation curve demonstrates complex behavior, increasing slowly in the range of the iron reversible potential, before rising again toward the nickel plateau. The 300-s OCP varies with SOC, and some of the curves do not stabilize during the 300-s relaxation time.

Figure 4d shows that, even at relatively low SOC, some of the potential relaxation curves first begin to rise near 300 s. Selected experiments were thus performed with a longer interruption time of $1800 \mathrm{~s}$. Results are shown in Figure 5 for both charge and discharge at a low rate. It can be seen, for example, that for a SOC of $180 \mathrm{C}$, the transition does not commence until nearly $900 \mathrm{~s}$ after the current is interrupted. A compromise is required in the design of the GITT to capture behavior that is representative of the cell during constantcurrent discharge. Thus in all other experiments, a 300-s relaxation time was employed. Clearly, analyses using GITT must consider the details of the experimental protocol.

Figure 6 shows potential transients during the interruption of discharge of electrodes with different iron loadings (3 wt $\% \mathrm{Fe}$ and 10 wt $\% \mathrm{Fe}$ ). Results are given for discharge rates of 50 and $250 \mathrm{~mA}$. As might be expected, the $10 \mathrm{wt} \% \mathrm{Fe}$ results are similar to those observed for $8 \mathrm{wt} \% \mathrm{Fe}$; for example, in Figures 1a and 1c, the SOC at which the transition occurs is about $250 \mathrm{C}$ for $8 \mathrm{wt} \% \mathrm{Fe}$ and $290 \mathrm{C}$ for 10 wt $\% \mathrm{Fe}$, while the transitions occur during charge around SOC of 145 $\mathrm{C}$ and $155 \mathrm{C}$. In contrast, for the $3 \mathrm{wt} \% \mathrm{Fe}$ cathode, the discharge and charge transitions are at approximately $180 \mathrm{C}$ and $110 \mathrm{C}$. Since the open-circuit relaxation from the iron to the nickel potential range
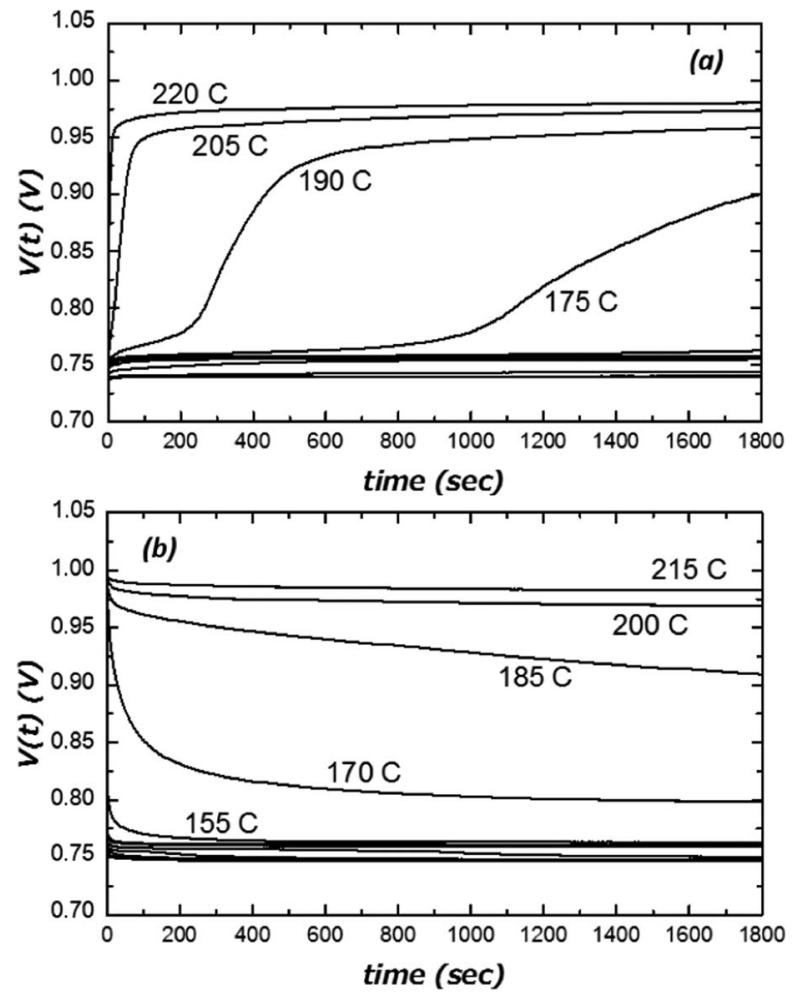

Figure 5. Open circuit potential as a function of time for different SOC (indicated in the figure). Results are for an $8 \mathrm{wt} \% \mathrm{Fe}$ positive electrode during (a) discharge at $50 \mathrm{~mA}$ and (b) charge at $50 \mathrm{~mA}$. In these experiments, the standard GITT protocol was modified to include relaxation times of $1800 \mathrm{~s}$. 

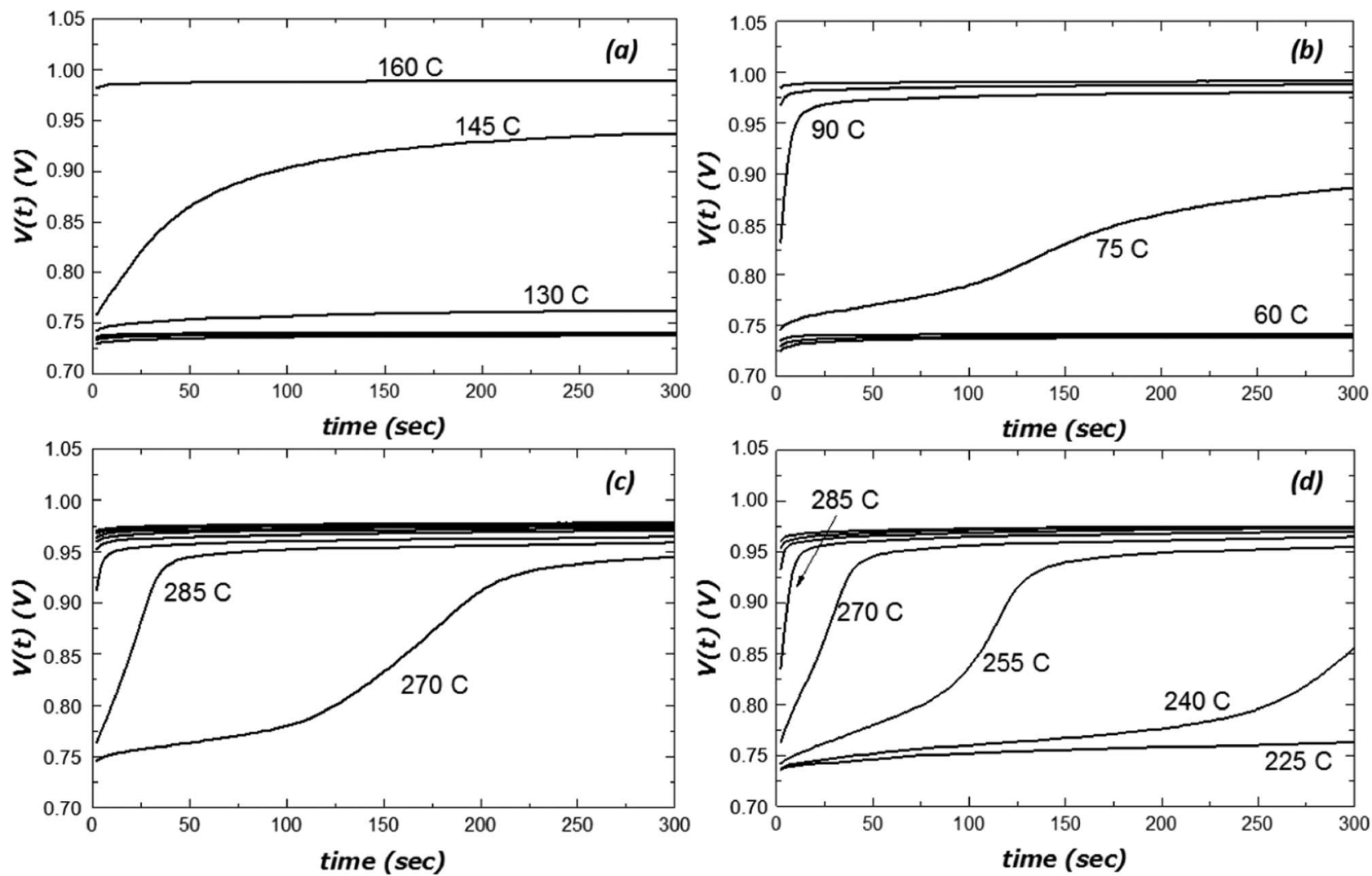

Figure 6. Open circuit potential during discharge as a function of time for different SOC (indicated in the figure). Results are shown for (a) 3 wt\% Fe cathode, rate of $50 \mathrm{~mA}$, (b) $3 \mathrm{wt} \% \mathrm{Fe}, 250 \mathrm{~mA}$, (c) $10 \mathrm{wt} \% \mathrm{Fe}, 50 \mathrm{~mA}$, and (d) $10 \mathrm{wt} \% \mathrm{Fe}, 250 \mathrm{~mA}$.

is related to unreacted $\mathrm{NiCl}_{2}$ remaining during discharge on the iron plateau, the relative amounts of nickel chloride and iron impact how transients evolve as a function of SOC.

\section{Discussion}

The OCP transitions show a rich behavior when the SOC is close to the transition from the nickel to iron plateaus. One feature of the discharge transients is that the OCP converges on a steady-state value that varies with SOC. For example in Figure 4, the steady-state OCP decreases by a few $\mathrm{mV}$ as the SOC is decreased beyond the $\mathrm{Ni} / \mathrm{Fe}$ transition SOC. These variations can been interpreted by assuming that $\mathrm{NiCl}_{2}$ and $\mathrm{FeCl}_{2}$ form a single, ideal $(\mathrm{Ni}, \mathrm{Fe}) \mathrm{Cl}_{2}$ phase, as experiments suggest. ${ }^{15}$ Then the Nernst equation can be written as:

$$
U_{\mathrm{NiCl}_{2} / \mathrm{Ni}}=U_{\mathrm{NiCl}_{2} / \mathrm{Ni}}^{\theta}+\frac{R T}{n_{e} \mathrm{~F}} \ln \left(\frac{a_{\mathrm{NiCl}_{2}}^{\mathrm{T}}}{a_{\mathrm{Ni}_{\mathrm{Cl}} a^{-}}^{2}}\right)
$$

where the activity of $\mathrm{Ni}$ in the metal alloy and in the chloride film may in general deviate from one. During most of discharge, we can reasonably assume that the molten electrolyte is chloride saturated and in equilibrium with solid $\mathrm{NaCl}$. If we assume that $a_{N i}=1$ (at least at the interface) and the surface of the triclinic phase is an ideal mixture, Equation 4 can be written as

$$
U_{\mathrm{NiCl}_{2} / \mathrm{Ni}}=1.00+\frac{R T}{2 \mathrm{~F}} \ln x_{\mathrm{NiCl} 2} \quad(\mathrm{vs} . \mathrm{Al} \mathrm{RE})
$$

where $x_{\mathrm{NiCl} 2}$ is mole fraction of nickel.

Figure 7 shows the resulting $x_{\mathrm{NiCl}_{2}}$ obtained from applying Equation 4 to the steady-state OCP in Figure 4. Results are given as a function of SOC for the $8 \mathrm{wt} \% \mathrm{Fe}$ cathode for the four rates. Where the OCP did not approach an asymptotic value, the values are not included in the graph. The nickel fraction is rate-independent in Figure 7. A value of $x_{\mathrm{NiCl} 2}=0.61$ is estimated from Equation 5 when the SOC $=200 \mathrm{C}$, the transition point estimated from the GITT data at $50 \mathrm{~mA}$ in Figure 3.

The very large excursions in OCP seen near the beginning of the iron plateau during discharge can be explained by a galvanic interaction between iron and nickel. Specifically,

$$
\mathrm{NiCl}_{2}+\mathrm{Fe}=\mathrm{Ni}+\mathrm{FeCl}_{2}
$$

The driving force for this reaction is $\sim 0.26 \mathrm{~V}$, suggesting that any $\mathrm{Fe}$ and $\mathrm{NiCl}_{2}$ co-existing during discharge may spontaneously react during the open circuit relaxation. As depicted in Figure 8, we hypothesize that:

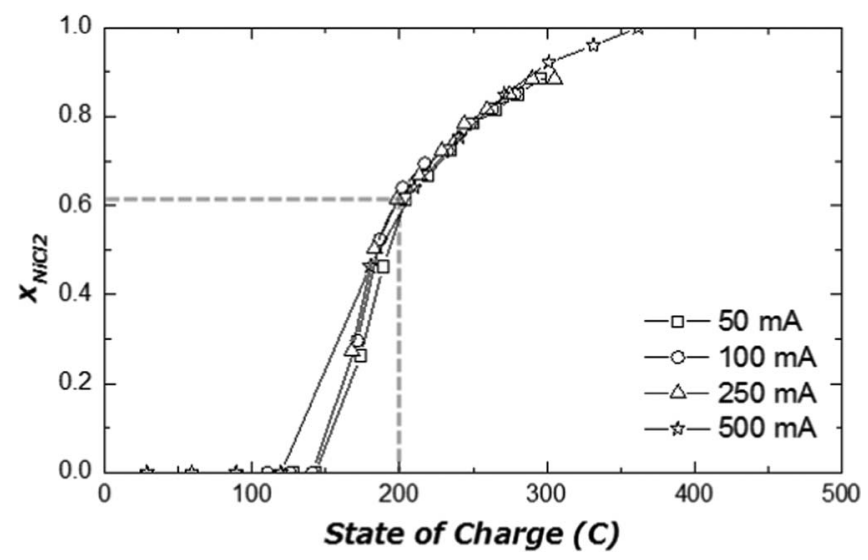

Figure 7. The mole fraction of $\mathrm{Ni}$ at the surface of the triclinic $(\mathrm{Ni}, \mathrm{Fe}) \mathrm{Cl}_{2}$ phase as a function of the state of charge, during discharge of an $8 \mathrm{wt} \% \mathrm{Fe}$ positive electrode. The mole fraction is estimated by applying Equation 5 to the steady-state OCP measurements in Figure 4. 


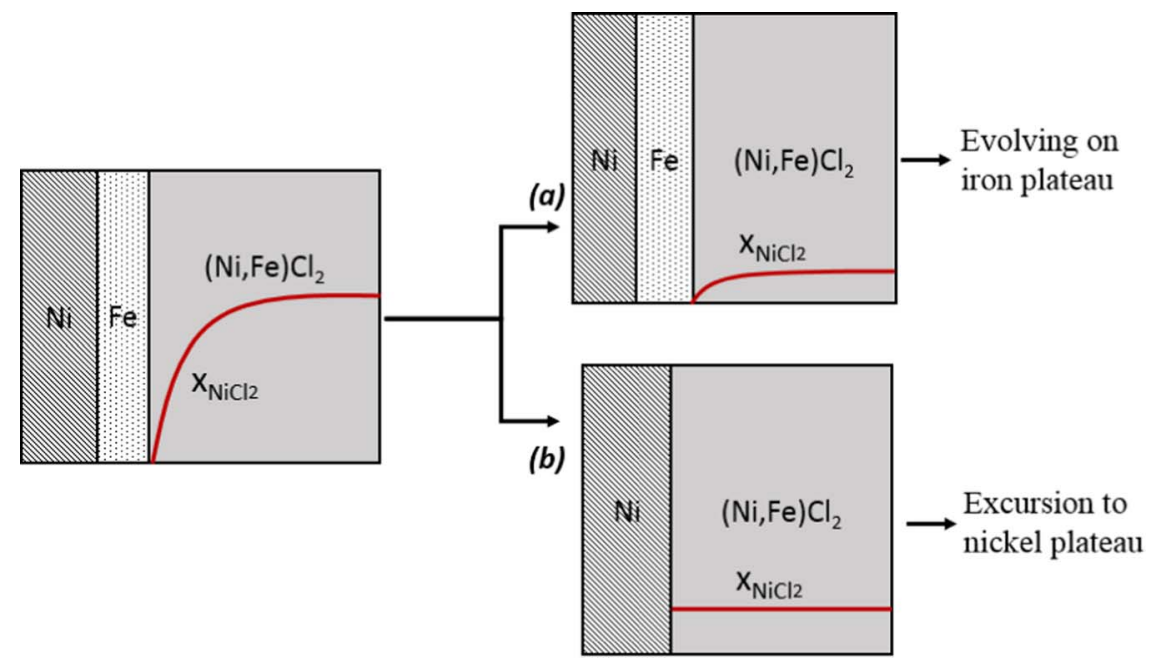

Figure 8. Schematic diagram showing the hypothesized galvanic interactions during the open circuit relaxation. Immediately after interruption of the current (a) both $\mathrm{Fe}$ metal and $\mathrm{NiCl}_{2}$ co-exist. Reaction 6 proceeds at a rate controlled by $\mathrm{NiCl}_{2}$ mass transfer to the interface. If $\mathrm{NiCl}_{2}$ is in stoichiometric excess, and given unlimited time, the reaction presumably continues until iron is completely consumed. If iron is in excess (b), the $\mathrm{NiCl}_{2}$ is either completely depleted or present in kinetically isolated small amount at the end of the interruption time.

1. a gradient of $\mathrm{Ni}$ and $\mathrm{Fe}$ exists within the triclinic phase. This can be understood ${ }^{10}$ because, while a single phase is believed to exist, the $\mathrm{NiCl}_{2}$ and $\mathrm{FeCl}_{2}$ are formed separately during charge and interdiffuse prior to complete reduction of the $\mathrm{NiCl}_{2}$ during discharge,

2. the reaction continues until either the iron-metal or the $\mathrm{NiCl}_{2}$ is completely consumed.

In Figure 8a, an instant after interruption, nickel chloride is depleted within the metal chloride film and Fe metal is present. During relaxation, the nickel ions diffuse through the film to react with iron metal according to Equation 6. If $\mathrm{NiCl}_{2}$ is in stoichiometric excess, once the iron is consumed, the only reversible reaction is the $\mathrm{Ni} / \mathrm{NiCl}_{2}$ couple, and the nickel depletion layer recovers, as depicted in Figure 8b. Once the iron is consumed, the nickel ion concentration profile relaxes toward its average value within the film.

In contrast, if the $\mathrm{Fe}$ metal is in excess, the potential relaxes to the $\mathrm{Fe} / \mathrm{FeCl}_{2}$ potential, either because $\mathrm{NiCl}_{2}$ is completely consumed or because the flux of $\mathrm{Ni}$ ions to the surface is so low that the iron is not consumed within $300 \mathrm{~s}$. This situation is shown schematically in Figure $8 \mathrm{a}$. Prediction of the dynamics of the curves requires an understanding of the reaction rates, including finite mass-transfer rates of $\mathrm{Ni}^{2+}$ to the surface. Regardless of mechanism, mass transfer is almost certainly important. Otherwise it is unlikely that the iron reduction reaction would commence prior to completion of the nickel reduction reaction. However, a prediction of mass transfer rates within the complex porous cathodes may be difficult without a full-scale porous-

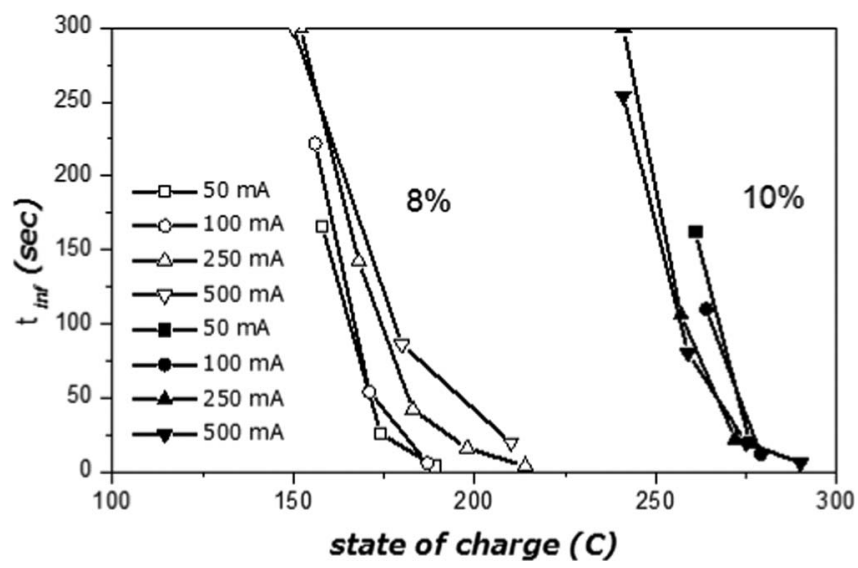

Figure 9. The characteristic time $\tau_{\text {inf }}$ of the OCP excursion from the iron to nickel plateau as a function of SOC for an (a) $8 \mathrm{wt} \%$ Fe cathode(a) and (b) 10 wt $\%$ Fe cathode. Results are shown for four discharge rates, indicated in the figures. electrode model, which is beyond the scope of the present paper. As a means of summarizing the results shown above, Figure 9 shows an inflection time $\tau_{\text {inf }}$ defined as the time required for the potential (starting below $0.85 \mathrm{~V}$ ) to exceed $0.85 \mathrm{~V}$ during open-circuit relaxations measured during discharge. The inflection time is shown as a function of the SOC. Results are only shown for the 8 and $10 \mathrm{wt} \% \mathrm{Fe}$ cathodes, as we captured few suitable OCP transients with the $3 \mathrm{wt} \%$ Fe electrodes.

During the charging process, the potential transients resulting from interruption appear to decay in an exponential manner. When the charging potential resides below the nickel oxidation potential, the OCP relaxes back to the iron plateau. Likewise when the oxidation potential exceeds the value on the thermodynamic potential for the nickel couple, the OCP relaxes to values near the nickel redox potential of 1.0 V. Large variations in potential from one plateau to another, as observed during discharge, are generally not seen, suggesting reaction 6 is not important. During charge, the iron oxidation goes nearly to completion prior to onset of nickel oxidation. This is in contrast to discharge, where iron reduction commences prior to exhaustion of the nickel-reduction reaction, hence, the significant discrepancy between charge and discharge in the sizes of the two plateaus.

The GITT experiments emphasize the complex interaction of the nickel and iron species within the positive electrode, especially during discharge. When coupled with simulations, the experiments can be used to refine hypothesized mechanisms, to interrogate models, and to determine physical parameters. They may also be used, after further development, as a diagnostic tool to characterize half cells and possibly full battery systems. For larger systems, spatial variations in the ratio of $\mathrm{Fe}$ to $\mathrm{NiCl}_{2}$ may be anticipated, and this will undoubtedly complicate analysis.

\section{Conclusions}

The behavior of mixed iron-nickel cathodes of sodium-metal chloride cells has been characterized by a GITT method, and the complex dynamic behavior of the OCP provides insight into iron- $\mathrm{NiCl}_{2}$ galvanic interactions. The OCP transients depend on the SOC, and are impacted by the amounts of iron-metal and nickel chloride present. During discharge, the asymptotic OCP is dependent on the SOC and is interpreted to provide a measure of the $\mathrm{Ni}: \mathrm{Fe}$ ratio in the triclinic $(\mathrm{Ni}$, $\mathrm{Fe}) \mathrm{Cl}_{2}$ film. A detailed analysis of the GITT transients, will require a model of the reaction and transport rates, and thus will provide a means for training full-scale battery models.

\section{Acknowledgments}

We thank David Bogdan, Job Rijssenbeek, Ashley Renko, Ayesha Gonsalves at General Electric and we acknowledge the financial support from the New York State Energy Research and Development 
Authority (NYSERDA) via the New York Battery and Energy Storage Technology Consortium (NY-BEST). NYSERDA has not reviewed the information contained herein, and the opinions expressed in this report do not necessarily reflect those of NYSERDA or the State of New York.

\section{References}

1. J. Coetzer, A new high energy density battery system. Journal of Power Sources, 18(4), 377 (1986)

2. P. A. Nelson, Advanced high-temperature batteries. Journal of Power Sources, 29(3), 565 (1990)

3. J. L. Sudworth, Zebra batteries. Journal of Power Sources, 51(1), 105 (1994).

4. H. Böhm and G. Beyermann, ZEBRA batteries, enhanced power by doping. Journal of Power Sources, 84(2), 270 (1999).

5. A. van Zyl, Review of the zebra battery system development. Solid State Ionics, 86-88, Part 2(0), 883 (1996).

6. J. Sudworth, The sodium/nickel chloride (ZEBRA) battery. Journal of power sources, 100(1-2), 149 (2001).
7. C.-H. Dustmann, Advances in ZEBRA batteries. Journal of Power Sources, 127(1-2), 85 (2004)

8. J. Prakash, L. Redey, and D. R. Vissers, Morphological considerations of the nickel chloride electrodes for zebra batteries. Journal of Power Sources, 84(1), 63 (1999).

9. E. C. Kluiters, et al., Testing of a sodium/nickel chloride (ZEBRA) battery for electric propulsion of ships and vehicles. Journal of Power Sources, 80(1), 261 (1999).

10. Saeed Khaleghi Rahimian, Ryan Ruixing Zhu, Michael Vallance, Badri Ramamurthi, and Alan C. West, Effect of Iron Doping on Sodium Nickel Metal Chloride Cell. 2015.

11. C. J. Wen, et al., Thermodynamic and Mass Transport Properties of "LiAl", Journal of The Electrochemical Society, 126(12), 2258 (1979).

12. W. Weppner and R. A. Huggins, Determination of the Kinetic Parameters of MixedConducting Electrodes and Application to the System $\mathrm{Li}_{3} \mathrm{Sb}$. Journal of The Electrochemical Society, 124(10), 1569 (1977).

13. J. Coetzer, G. D. Wald, and S. W. Orchard, Mechanism of the cathode reaction in sodium-ferrous chloride secondary cells. Journal of Applied Electrochemistry, 23(8), 790 (1993).

14. R. C. C. Galloway, The ZEBRA electric vehicle battery: power and energy improvements. Journal of power sources, 80(1-2), 164 (1999).

15. J. Rijssenbeek, et al., In situ X-ray diffraction of prototype sodium metal halide cells: Time and space electrochemical profiling. Journal of Power Sources, 196(4), 2332 (2011). 